\title{
Improvements in Immune Function and Activation with 48-Week Darunavir/Ritonavir-Based Therapy: GRACE Substudy
}

\author{
Christos Tsoukas, ${ }^{1}$ Louise Gilbert, ${ }^{2}$ Trevor Lewis, ${ }^{1}$ George Hatzakis, ${ }^{3}$ \\ Ron Falcon, ${ }^{4}$ and Joseph Mrus ${ }^{4}$ \\ ${ }^{1}$ Department of Microbiology and Immunology, McGill University Health Centre, Room A5-140, 1650 Cedar Avenue, \\ Montreal, QC, Canada H3G 1A4 \\ ${ }^{2}$ Montreal General Hospital, Flowcytometry Laboratory, 1650 Cedar Avenue, Room C10-166, Montreal, QC, Canada H3G $1 A 4$ \\ ${ }^{3}$ LAC+USC Medical Center, 1200 N State Street, Room IPT-C4E100, Los Angeles, CA 90033, USA \\ ${ }^{4}$ Janssen Services, LLC, Clinical Affairs, 1125 Trenton-Harbourton Road, Titusville, NJ 08560, USA
}

Correspondence should be addressed to Christos Tsoukas; chris.tsoukas@muhc.mcgill.ca

Received 12 August 2013; Accepted 17 November 2013

Academic Editors: G. D’ettorre and C. Petrovas

Copyright (C) 2013 Christos Tsoukas et al. This is an open access article distributed under the Creative Commons Attribution License, which permits unrestricted use, distribution, and reproduction in any medium, provided the original work is properly cited.

\begin{abstract}
Objective. During the course of HIV infection, progressive immune deficiency occurs. The aim of this prospective substudy was to evaluate the recovery of functional immunity in a subset of patients from the GRACE (Gender, Race, And Clinical Experience) study treated with a DRV/r-based regimen. Methods. The recovery of functional immunity with a darunavir/ritonavir-based regimen was assessed in a subset of treatment-experienced, HIV-1 infected patients from the GRACE study. Results. 19/32 patients (59\%) enrolled in the substudy were virologically suppressed $(<50$ copies $/ \mathrm{mL}$ ). In these patients, median (range) CD4+ cell count increased from $222(2,398)$ cells $/ \mathrm{mm}^{3}$ at baseline to $398(119,812)$ cells $/ \mathrm{mm}^{3}$ at Week 48 . CD8+\% decreased significantly from baseline to Week 48 $(P=.03)$. Proliferation of CD4+ lymphocytes in response to CD3+/CD28+, phytohemagglutinin, and pokeweed was significantly increased $(P<.01)$ by Week 12 . Proliferation in response to Candida and tetanus was significantly increased by Week $48(P<.01$ and $P=.014$, resp.). Staphylococcal enterotoxin B-stimulated tumor necrosis factor-alpha and interleukin-2 in CD4+ cells was significantly increased by Week $12(P=.046)$ and Week $48(P<.01)$, respectively. Conclusions. Darunavir/ritonavir-based therapy demonstrated improvements in CD4+ cell recovery and association with progressive functional immune recovery over 48 weeks. This trial is registered with NCT00381303.
\end{abstract}

\section{Introduction}

During the course of HIV-1 infection, multifactorial Tlymphocyte (T-cell)-mediated mechanisms contribute to the progressive loss of host immune function [1-5]. In infected individuals, immune dysregulation occurs early and is characterized by a decrease in CD4+ cell count, a concurrent rise in CD8+ cells, a progressive decline in the CD4+/CD8+ ratio, and defective thymocyte proliferation [6]. During late-stage disease, loss of T-cell homeostasis also occurs $[7,8]$.

$\mathrm{T}$ cells are chronically activated throughout the course of HIV infection, as indicated by an increase in the expression of the antigens Ki67, CD38, and human leukocyte antigen (HLA)-DR, with CD38 recognized as the most reliable marker of immune activation [1-3, 5, 9]. Immune activation provides the virus with a steady pool of target cells and has been linked with increased polyclonal T-cell proliferation and turnover, as well as increases in the apoptotic marker CD95 [10-13] and activation-induced cell death [12, 14-16].

Concomitant with the decline of CD4 cells in the peripheral blood, the frequency of the CD4+ CD28 null subset increases with disease progression and eventual progression to AIDS [10]. The presence of CD28 on T cells is critically important for the generation of T-cell responses. Interaction of this costimulatory molecule with its ligands increases the expression of antiapoptotic proteins and improves interleukin (IL)-2 production. The increase in circulation of T cells with a CD4+ CD28 null phenotype is consistent with 
a process known as replicative senescence [11, 13, 17-19]. T cells that lack CD28 surface expression are nonanergic, oligoclonally expanded, and terminally differentiated, with limited replicative capacity and increased sensitivity to apoptosis $[20,21]$. These alterations in phenotype are accompanied by cytokine changes consistent with a chronic proinflammatory state. The failure to produce adequate amounts of IL-2 leads to a marked functional impairment of cellular and humoral immunity. Reduced IL-2 expression has been associated with a shift from Th1 cytokine responses to Th2 cytokine responses. It has been postulated that the Th1/Th2 imbalance may result in cellular immunity deficiency [4].

The dysregulation of cytokine secretion during the course of HIV infection has been examined using a wide range of methods, including enzyme-linked immunosorbent assay, reverse transcriptase-polymerase chain reaction, Tcell cloning, and, more recently, flow cytometric intracellular cytokine detection [4]. Of these methods, only flow cytometry allows quantitative and qualitative determination of cytokine expression patterns in individual T cells [4].

Successful antiretroviral (ARV) therapy results in improvements in circulating CD4+ T-cell levels with decreases in CD8+ counts and declines in immune activation and CD95 expression $[1-5,7,9,22-26]$. Limited data on replicative senescence suggest a lack of significant improvement in the short term, despite adequate HIV suppression [10]. Some studies have suggested that protease inhibitor- (PI-) based regimens may have a greater effect on $\mathrm{CD} 4+$ count recovery than nonnucleoside reverse transcriptase inhibitor-based regimens $[27,28]$. Some of the previous studies on immune recovery with ARV therapy have been cross-sectional in design, conducted primarily in white males, and focused on absolute CD4+ count or CD $4+\%$ recovery. Furthermore, most of these studies did not comprehensively assess the functional aspects of immune recovery [29]. Of the studies that did evaluate the influence of ARV therapy on functional immune parameters, most were drug class specific [30-32].

GRACE (Gender, Race, And Clinical Experience) is the largest ARV trial to focus on women with HIV-1 in North America and was designed to assess sex-based and racebased differences in efficacy, safety, and tolerability of the PI darunavir with low-dose ritonavir (DRV/r) plus an optimized background regimen over 48 weeks in a diverse, treatmentexperienced patient population [33]. The aim of this prospective substudy was to quantitatively and qualitatively evaluate the recovery of functional immunity (T-cell function) with a DRV/r-based regimen in a subset of patients from the GRACE study.

\section{Materials and Methods}

2.1. Study Design and Patients. GRACE was a multicenter, open-label, single-arm, Phase IIIb study conducted at 65 sites across USA, Puerto Rico, and Canada that enrolled 429 treatment-experienced patients (viral load $\geq 1000$ HIV1 RNA copies $/ \mathrm{mL}$ ) aged at least 18 years with documented HIV-1 infection [33]. Full inclusion and exclusion criteria and the study flow diagram have been reported [33]. Patients received DRV/r 600/100 mg twice daily plus an investigatorselected background regimen that could include etravirine. Patients at participating GRACE study sites were eligible for the prospective immunology substudy, which aimed to enroll up to 100 subjects. A group of healthy, HIV seronegative volunteers were included for comparison.

2.2. Ethics Statement. The research has complied with all federal guidelines and institutional policies. All subjects were required to sign a separate, Independent Ethics Committee/Institutional Review Board (IRB) informed consent form specific to this substudy. The IRBs were Quorom Review Inc., Seattle, WA, Office of Human Research Ethics-UNC IRB, Chapel Hill, NC, and AIDS Research Consortium of Atlanta, Atlanta, GA. Each IRB approved of this study. The study was conducted in accordance with the principles of the Declaration of Helsinki and followed Good Clinical Practice guidelines.

2.3. Study Evaluations. Viral suppression in this analysis was defined as achieving HIV-1 RNA less than 50 copies $/ \mathrm{mL}$ at Week 48. Immune function and phenotype were determined by flow cytometry at baseline and Weeks 12 and 48 in virologically suppressed and nonsuppressed patients. Changes in immune phenotype were determined from subsets of CD4+ and CD8+ T cells, with immune activation defined as increased expression of T-cell CD38 and HLA-DR surface markers, and immune replicative senescence by increased frequency of circulating CD28 null $\mathrm{T}$ cells. Changes in immune function were assessed by lymphocyte proliferation in response to Candida and tetanus (recall antigens), phytohemagglutinin (PHA) and pokeweed (mitogenic plant lectins), and $\mathrm{CD} 3+/ \mathrm{CD} 28+$ and by intracellular cytokine expression of IL-2, interferon-gamma (IFN- $\gamma$ ), and tumor necrosis factor-alpha (TNF- $\alpha$ ) in response to staphylococcal enterotoxin B.

2.4. Immunophenotyping. A whole blood lysing technique was used and subpopulations were assessed according to a standard protocol for 3-color and 4-color immunofluorescence flow cytometry using fluorochrome conjugated monoclonal antibodies and a fluorescence activated cell sorter. A panel of monoclonal antibodies was used to delineate total $\mathrm{CD} 3+$, total $\mathrm{CD} 4+$ and $\mathrm{CD} 8+\mathrm{T}$ cells, $\mathrm{CD} 4+/ \mathrm{CD} 8+$ ratio, activated $\mathrm{T}$ cells $(\mathrm{CD} 38+/ \mathrm{HLA}-\mathrm{DR}+)$, immune replicative senescence (CD4+/CD28+ or CD8+/CD28+), and apoptotic cells (CD95+).

2.5. Proliferation Assays. The Vybrant CFDA SE Cell Tracer Kit (Molecular Probes, Inc.) was used. Lymphocytes were labeled with carboxyfluorescein diacetate and succinimidyl ester CFDA SE and then incubated at $37^{\circ} \mathrm{C}$ with $5 \%$ carbon dioxide for 7 days. The label is inherited by daughter cells after division. Labeled lymphocytes with carboxyfluorescein diacetate and succinimidyl ester were detected by flow cytometry using CD45 markers for gating strategy. This method quantified mitogenic and recall antigen responses. 


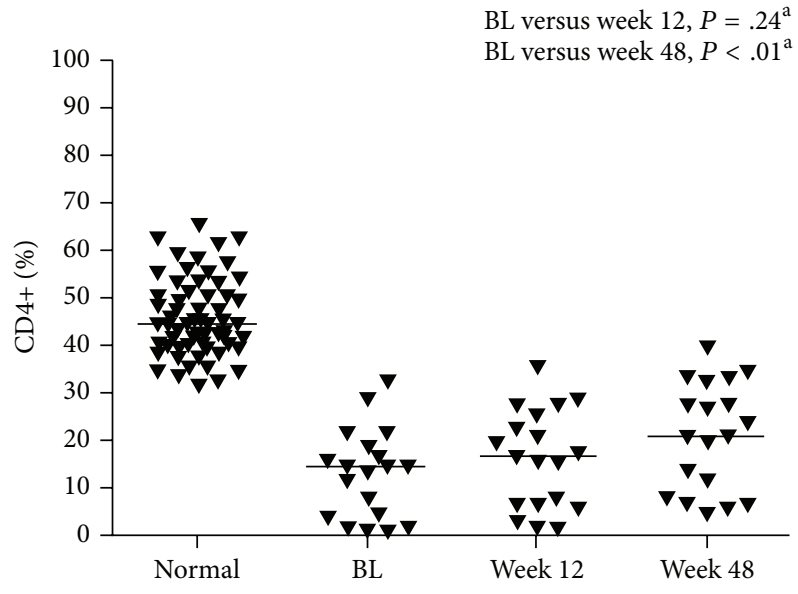

(a)

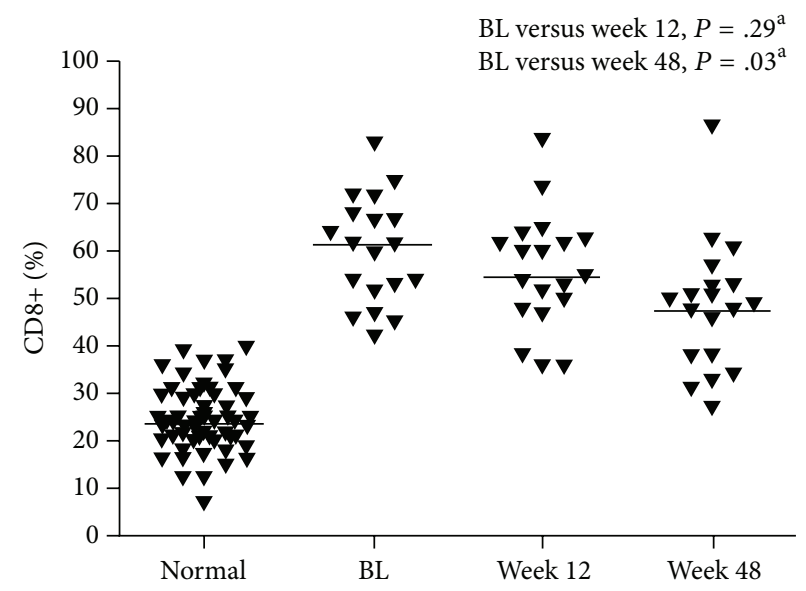

(b)

BL versus week $12, P=.14^{\mathrm{a}}$

BL versus week $48, P<.01^{\text {a }}$

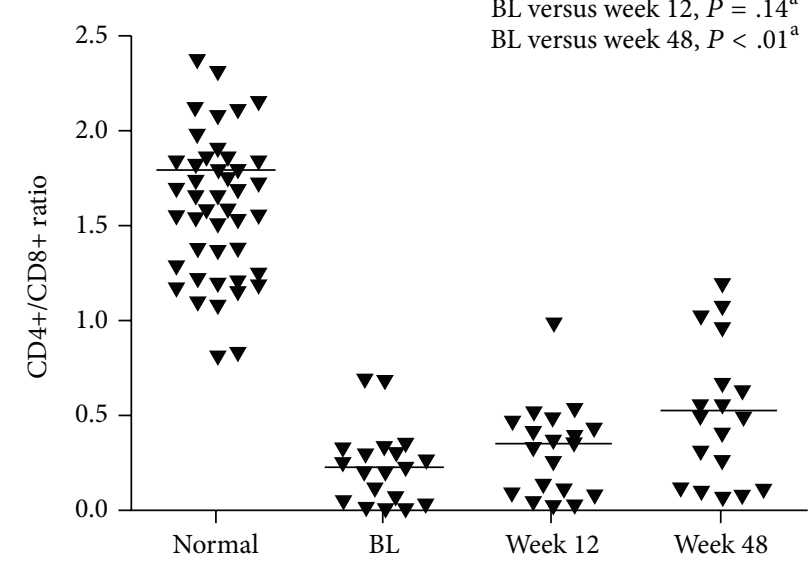

(c)

Figure 1: (a) Percent CD4+, (b) percent CD8+, and (c) CD4+/CD8+ ratio in virologically suppressed patients. Line represents median; ${ }^{\mathrm{a}}$ Wilcoxon rank-sum test; BL: baseline.

The reagents used were Candida, tetanus, CD3+/CD28+, PHA, and pokeweed.

2.6. Intracellular Cytokines. Flow cytometric intracellular cytokine detection of Thl cytokines including IFN- $\gamma$, IL-2, and TNF- $\alpha$ was assessed using the BD Cytofix/Cytoperm Plus Fixation/Permeabilization (GolgiPlug protein transport inhibitor; BD Biosciences). Peripheral blood mononuclear cells were stimulated with staphylococcal enterotoxin B (Sigma) and a CEF control peptide pool (CMV, EBV, Influenza virus; NIH reagent 9808). This stimulation step was followed by the fixation and permeabilization of the cells. Then, surface and intracellular staining antibodies were added in a single staining step (AntiHu-IFN- $\gamma / \mathrm{CD} 69 / \mathrm{CD} 4 / C D 3$, Anti-Hu-IL2/CD69/CD4/CD3, Anti-Hu-TNF- $\alpha / C D 69 / C D 4 / C D 3 ; B D$ Biosciences). Cells were acquired and analyzed by flow cytometry.

2.7. Statistical Analysis. Immune recovery was evaluated in continuous and categorical outcome analyses. Wilcoxon rank-sum tests were used to assess immune parameter changes from baseline.

\section{Results}

3.1. Patient Population and Baseline Characteristics. A total of 32 patients with HIV-1 were enrolled in the substudy; 25 (78\%) patients had Week 48 data and 19 (59\%) were virologically suppressed at Week 48 . The normal comparator group consisted of 34 healthy, HIV-seronegative individuals, $17(50 \%)$ of whom were women and $25(74 \%)$ of whom were white. Patient demographics and baseline characteristics for total and virologically suppressed patients are shown in Table 1.

3.2. Immune Phenotype. The median (range) CD4+ count at baseline for the total patient population was 191 (2, 463 ) and the median (range) CD4+ count in virologically suppressed patients at baseline was $222(2,398)$ cells $/ \mathrm{mm}^{3}$ (Table 1). At Week 48, the median (range) CD4+ count for the total population and virologically suppressed patients 
TABLE 1: Demographics and baseline characteristics of patients enrolled into the immunology substudy of GRACE.

\begin{tabular}{|c|c|c|c|}
\hline Parameter & & $\begin{array}{l}\text { All HIV+ patients } \\
\qquad(N=32)\end{array}$ & $\begin{array}{c}\text { Virologically } \\
\text { suppressed }^{\mathrm{a}} \text { patients at Wk } \\
48(n=19)\end{array}$ \\
\hline \multirow{2}{*}{ Sex, $n(\%)$} & Men & $19(59.4)$ & $13(68.4)$ \\
\hline & Women & $13(40.6)$ & $6(31.6)$ \\
\hline \multirow{3}{*}{ Race, $n(\%)$} & Black & $15(46.9)$ & $8(42.1)$ \\
\hline & Hispanic & $10(31.3)$ & $6(31.6)$ \\
\hline & White & $7(21.9)$ & $5(26.3)$ \\
\hline Mean (SD) viral load, $\log _{10}$ copies $/ \mathrm{mL}$ & & $4.74(0.84)$ & $4.76(0.82)$ \\
\hline Median (range) CD4+ count, cells $/ \mathrm{mm}^{3}$ & & $191(2,463)$ & $222(2,398)$ \\
\hline
\end{tabular}

${ }^{a} \mathrm{HIV}-1 \mathrm{RNA}<50$ copies/mL at Wk 48 (or at Wks 36 and 52 if a Wk 48 sample was not available).

TABLE 2: Immune phenotype over the course of the GRACE immunology substudy.

\begin{tabular}{|c|c|c|c|c|c|c|}
\hline \multirow{2}{*}{ Median (range) } & \multicolumn{2}{|c|}{ Baseline } & \multicolumn{2}{|c|}{ Wk 12} & \multicolumn{2}{|c|}{ Wk 48} \\
\hline & $\mathrm{All}^{\mathrm{a}}$ & Suppressed $^{\mathrm{b}}$ & $\mathrm{All}^{\mathrm{a}}$ & Suppressed $^{\mathrm{b}}$ & $\mathrm{All}^{\mathrm{a}}$ & Suppressed $^{\mathrm{b}}$ \\
\hline $\mathrm{CD} 4+(\%)$ & $15(1,33)$ & $15(1,33)$ & $16(2,36)$ & $17(2,36)$ & $21(3,40)$ & $21(5,40)$ \\
\hline $\mathrm{CD} 8+(\%)$ & $60.5(39,83)$ & $62(42,83)$ & $59(35,84)$ & $55(36,84)$ & $50(27,87)$ & $49(27,87)$ \\
\hline CD4+/CD8+ ratio (\%) & $0.22(0.01,0.70)$ & $0.22(0.01,0.70)$ & $0.30(0.03,1.00)$ & $0.36(0.03,1.00)$ & $0.41(0.04,1.21)$ & $0.52(0.08,1.21)$ \\
\hline $\mathrm{CD} 4+/ \mathrm{CD} 38+/ \mathrm{DR}+(\%)$ & $22.5(10,88)$ & $22(10,88)$ & $19(9,76)$ & $18(9,53)$ & $13(2,36)$ & $11(2,36)$ \\
\hline CD8+/CD38+/DR+ (\%) & $48.5(18,76)$ & $47(18,76)$ & $36.5(11,71)$ & $34(11,62)$ & $25(4,68)$ & $22(4,52)$ \\
\hline CD4+/CD95+ (\%) & $15(1,35)$ & $16(1,35)$ & $21(3,38)$ & $22(3,38)$ & $23(4,41)$ & $24(6,41)$ \\
\hline CD8+/CD95+ (\%) & $71.5(40,87)$ & $70(40,87)$ & $69.5(44,88)$ & $66(44,88)$ & $55(32,80)$ & $49(32,79)$ \\
\hline $\mathrm{CD} 3+/ \mathrm{CD} 4+/ \mathrm{CD} 28+(\%)$ & $93(46,99)$ & $95(56,99)$ & $94(67,100)$ & $94(70,100)$ & $96(67,99)$ & $96(67,99)$ \\
\hline $\mathrm{CD} 3+/ \mathrm{CD} 8+/ \mathrm{CD} 28+(\%)$ & $59.5(39,86)$ & $62(39,85)$ & $50(39,79)$ & $50.5(39,79)$ & $56(23,82)$ & $56(35,82)$ \\
\hline
\end{tabular}

${ }^{\mathrm{a}} n=32$ at baseline, $n=30$ at Wk 12 and $n=25$ at Wk 48; ${ }^{\mathrm{b}} \mathrm{HIV}-\mathrm{RNA}<50$ copies/mL at Wk 48 (or at Wks 36 and 52 if a Wk 48 sample was not available), $n=19$.

was $337(98,812)$ and $398(119,812)$ cells $/ \mathrm{mm}^{3}$, respectively. In virologically suppressed patients, the $\mathrm{CD} 4+\%$ increased significantly from baseline to Week $48(P<.03$; Figure 1$)$. The median (range) CD8+ count at baseline for the total patient population was $912.5(288,3131)$ cells $/ \mathrm{mm}^{3}$, while the median (range) CD8+ count in virologically suppressed patients at baseline was $1037(288,3131)$ cells $/ \mathrm{mm}^{3}$. The CD8+\% decreased significantly from baseline to Week 48 $(P<.01)$ in virologically suppressed patients (Figure 1$)$. The median (range) $\mathrm{CD} 4+/ \mathrm{CD} 8+$ ratio at baseline was 0.22 $(0.01,0.70)$ in all patients and $0.22(0.01,0.70)$ in virologically suppressed patients. The CD4+/CD8+ ratio at Weeks 12 and 48 is displayed in Figure 1 and Table 2. The CD4+/CD8+ ratio increased significantly from baseline to Week $48(P<.01)$ in suppressed patients. The percentage of $\mathrm{CD} 4+$ and $\mathrm{CD} 8+$ cells at Weeks 12 and 48 in suppressed patients is shown over 48 weeks in Figure 1. The percentage of CD4+ cells significantly increased $(P<.01)$ and CD8+ cells significantly decreased $(P=.03)$ from baseline to Week 48.

Improvements in immune activation, as measured by decreases in CD38 and HLA-DR expression on CD4+ and CD8+ cells over the course of the study, were observed in both the total patient population (Table 2) and in virologically suppressed patients (Table 2; Figure 2).

The percentage of apoptotic (CD95+) CD4+ cells in suppressed patients significantly increased from baseline to
Week $48(P=.0142$; Table 2; Figure 2). The percentage of apoptotic CD8+ cells, on the other hand, significantly decreased from baseline to Week 48 in suppressed patients $(P=.0025$; Table 2; Figure 2).

Changes in immune replicative senescence were measured by changes in the frequency of $\mathrm{CD} 4+/ \mathrm{CD} 28-$ or CD8+/CD28- cells (Table 2). There was little change in the expression of costimulatory marker CD28+ on CD4+ cells from baseline to Week 48 in the total patient population or the virologically suppressed group (Table 2). There was a small decrease in the expression of CD28+ on CD8+ cells in the total patient population and the virologically suppressed population from baseline to Week 48 (Table 2).

3.3. Immune Function. The ability of CD4+ lymphocytes to respond to mitogens and recall antigens improved in GRACE patients over the course of the study. Proliferation in response to $\mathrm{CD} 3+/ \mathrm{CD} 28+$ and PHA was at, or near, normal levels by Week 12 in virologically suppressed patients, and proliferation in response to pokeweed and Candida was at normal levels by Week 48 (Figure 3). Intracellular production of TNF- $\alpha$ and IL-2 also increased during the study. Tumor necrosis factor-alpha and IL-2 significantly increased in staphylococcal enterotoxin B-stimulated CD4+ cells of virologically suppressed patients by Week 48 ; there 


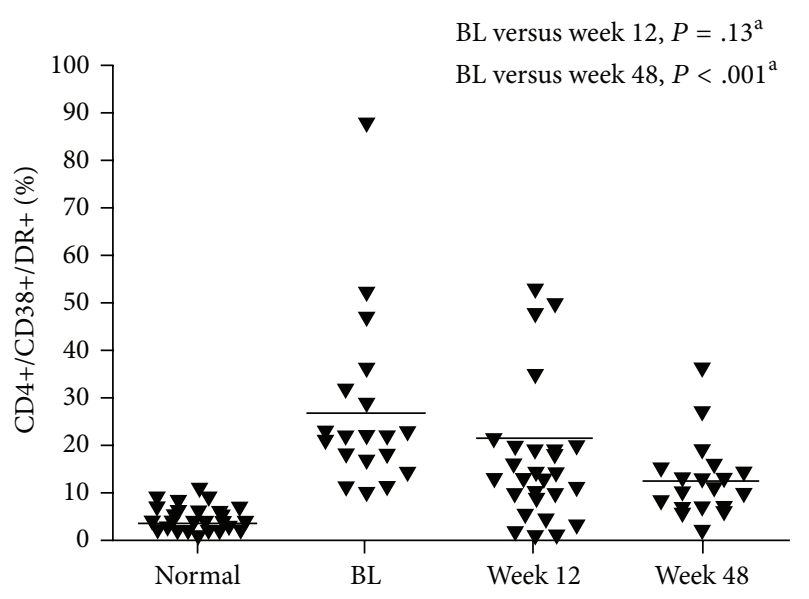

(a)

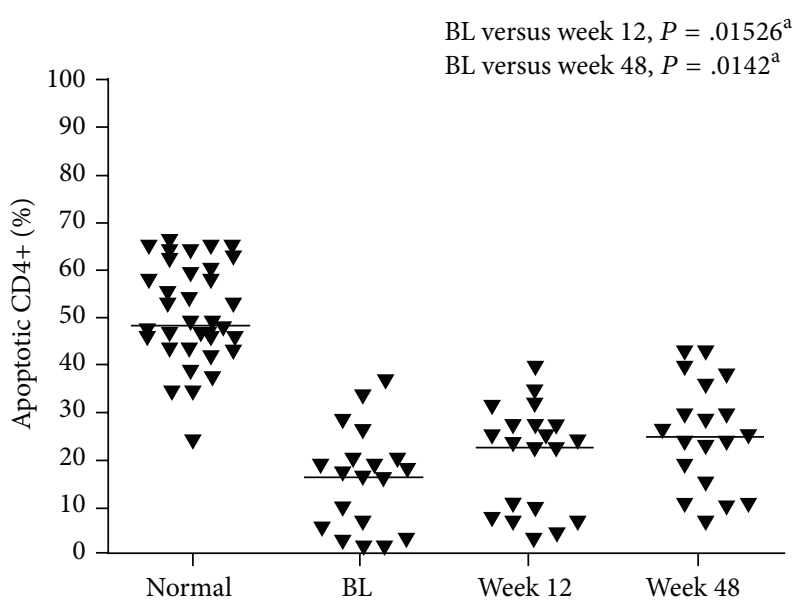

(c)

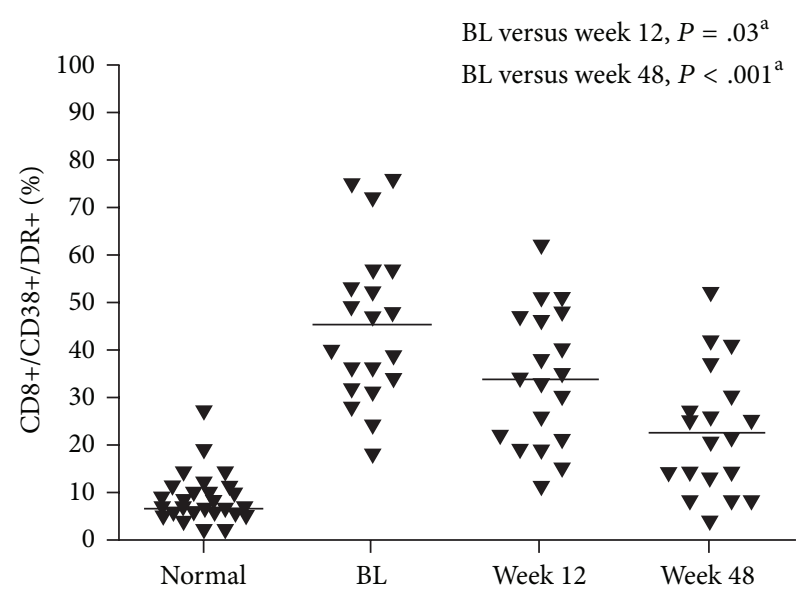

(b)

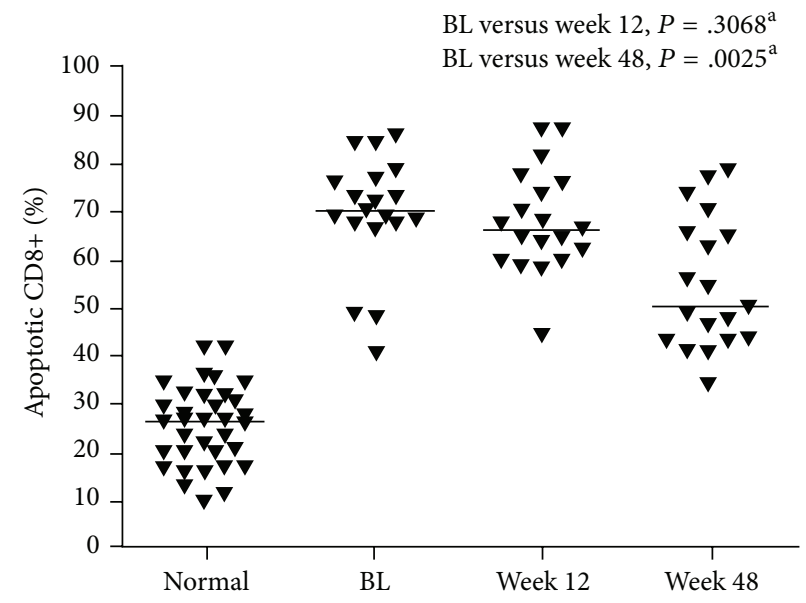

(d)

Figure 2: (a) CD4+/CD38+/DR+, (b) CD8+/CD38+/DR+, percentage of apoptotic T cells, (c) CD4+/CD95+, (d) CD8+/CD95+. Line represents median; ${ }^{\mathrm{a}}$ Wilcoxon rank-sum test; $\mathrm{BL}$ : baseline.

was no significant change in IFN- $\gamma$ in the stimulated CD4+ cells (Figure 4).

\section{Discussion}

Few published studies within clinical trials have prospectively assessed in vitro changes in immune function as measured by lymphocyte proliferation $[34,35]$, and none of these assessed intracellular cytokine production in response to ARV therapy. This substudy from the GRACE trial evaluated T-cell function in a racially diverse, treatment-experienced population comprised of more than $30 \%$ women. As expected, based on results from previous studies [24, 27, 28], DRV/rbased therapy resulted in increases in CD4+ cell counts and decreases in CD8+ counts in virologically suppressed patients, with an improved CD4+/CD8+ ratio. In addition, we found that DRV/r-based ARV therapy was associated with progressive functional immune recovery over 48 weeks in virologically suppressed patients, as demonstrated by improved lymphocyte response to mitogens and recall antigens. This suggests that not only do the CD4+ cell counts of
HIV-1-infected patients improve during DRV/r-based therapy, but their ability to respond in vitro to immune stimuli may improve as well. Results from this report are consistent with a recent study that demonstrated significant decreases in immune activation and apoptosis in CD4+ and CD8+ T cells and a decrease in immune CD8+ senescence following ARV therapy [36].

While there have been studies evaluating the influence of ARV therapy on immune parameters, data typically represent class-specific rather than regimen-specific treatment approaches. For example, therapy with integrase inhibitors has been shown to result in larger CD4+ cell count increases compared with other ARV classes [29, 37, 38]. The work shown here represents a regimen-specific study, with combination $\mathrm{DRV} / \mathrm{r}$ treatment in addition to an optimized background regimen that could differ across patients. Unfortunately, we cannot assess differences between regimens, as our study was not comparative.

The reduction in T-cell activation seen here has previously been shown to correlate with the reduction in viral load, as well as an improved response to recall antigens 


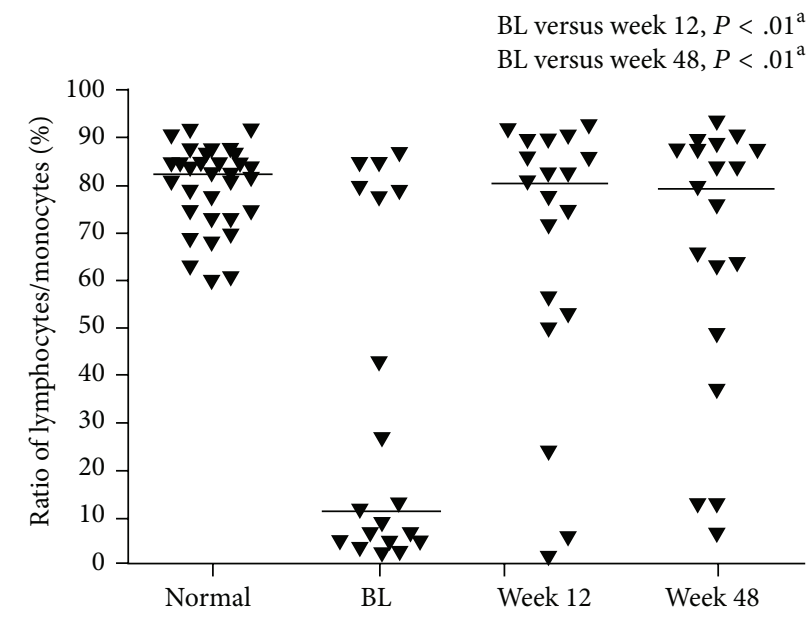

(a) $\mathrm{CD} 3+/ \mathrm{CD} 28+$

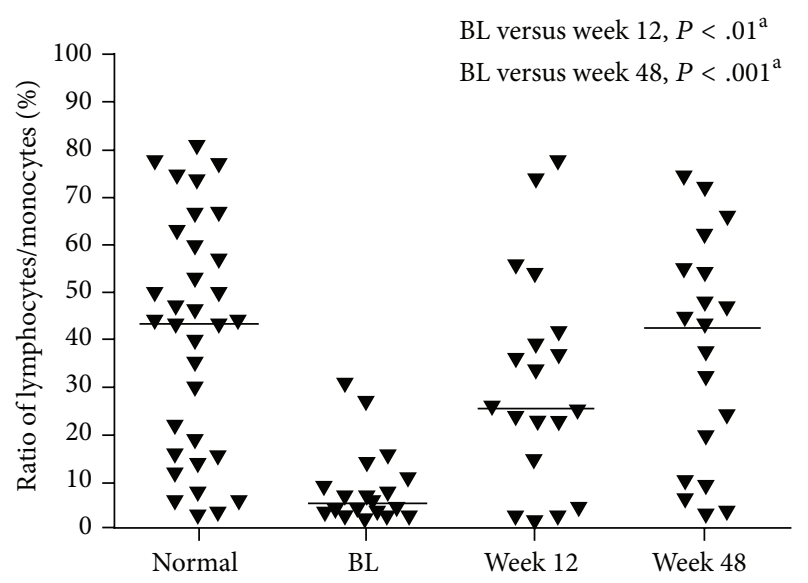

(c) Pokeweed

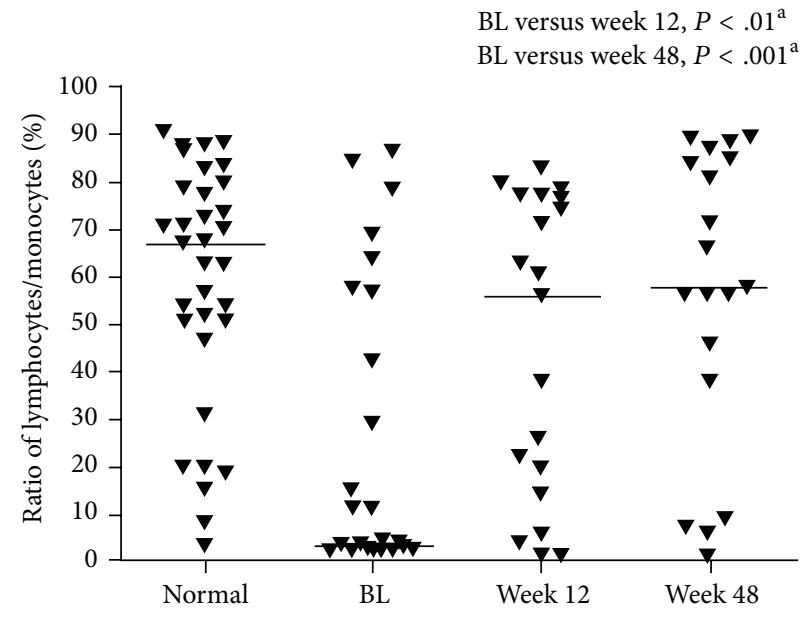

(b) PHA

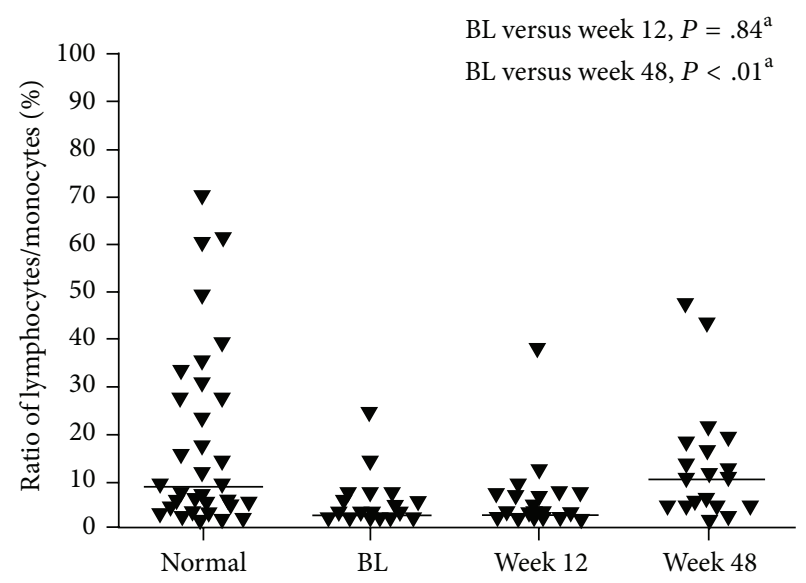

(d) Candida

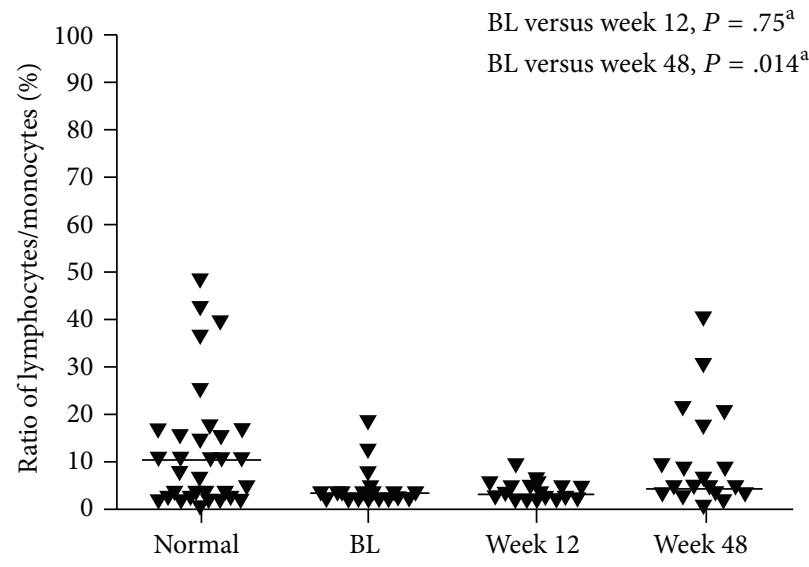

(e) Tetanus

FIGURE 3: CD4+ lymphocyte proliferation in (a) CD3+/CD28+, (b) phytohemagglutinin, (c) pokeweed, (d) Candida, and (e) tetanus. Line represents median; ${ }^{a}$ Wilcoxon rank-sum test; BL: baseline; PHA: phytohemagglutinin.

[24]. The observed HIV-1-induced increase in apoptotic CD95+/CD4+ cells has been suggested to be independent of ARV activity; the PI saquinavir has been shown to decrease CD95 expression in CD4+ cells from healthy donors whose cells were previously briefly incubated with HIV-1 virus
[25]. Although anti-CD95-induced apoptosis declines with therapy, this change is only occasionally associated with a reduction in expression of CD95 on T lymphocytes [39]. It is thus not surprising that in our study CD95 expression on $\mathrm{T}$ cells did not decline. In the GRACE study, no improvement 


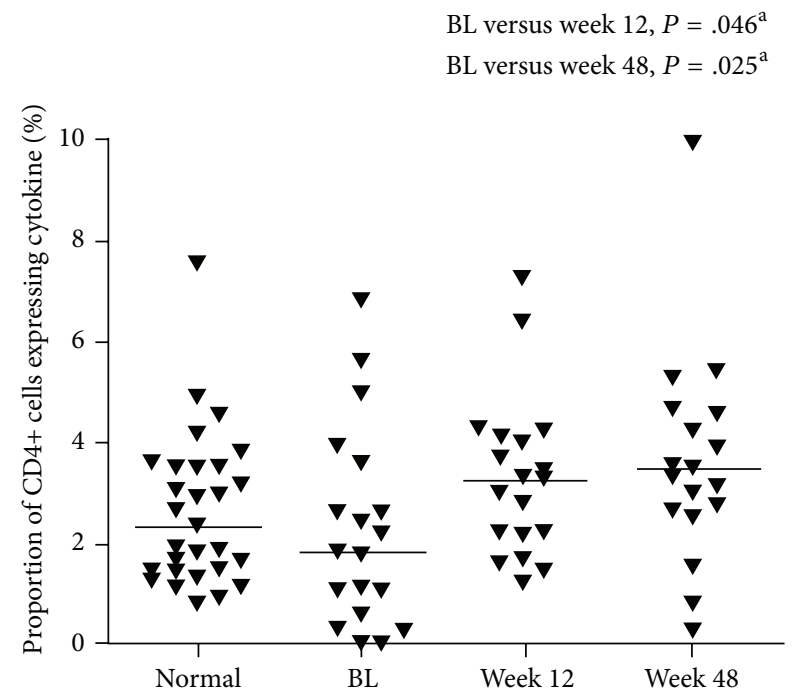

(a) SEB-stimulated TNF- $\alpha$ in CD4+ cells

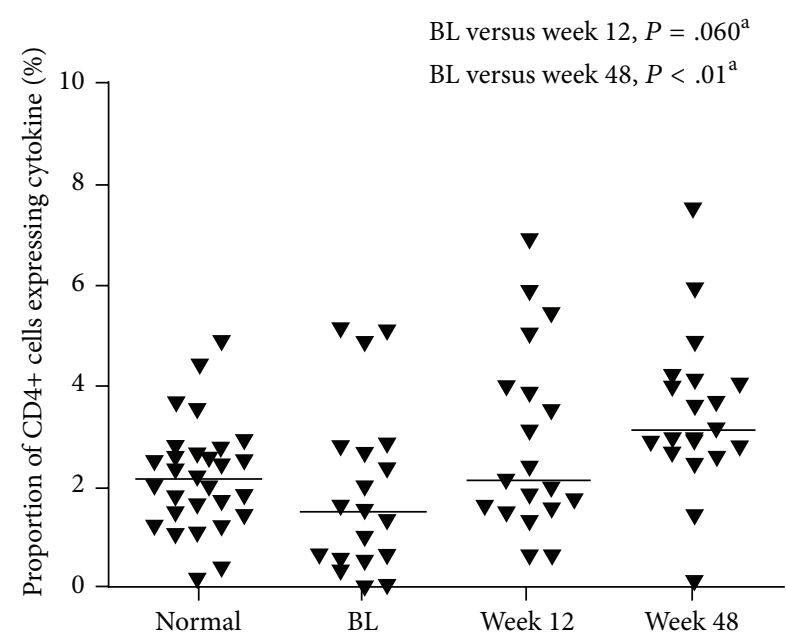

(c) SEB-stimulated IL-2 in CD4+ cells

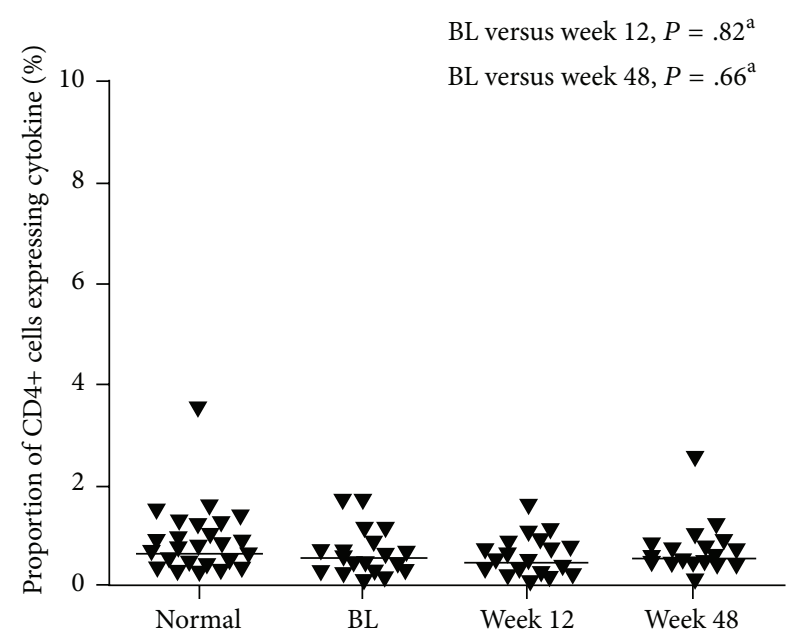

(e) SEB-stimulated IFN- $\gamma$ in CD4+ cells
BL versus week $12, P=.82^{\mathrm{a}}$

BL versus week $48, P=.47^{\mathrm{a}}$

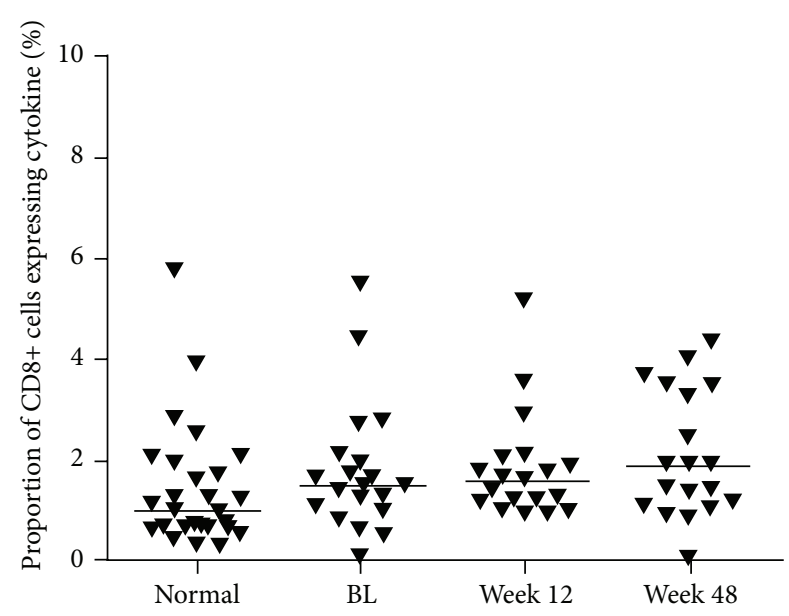

(b) SEB-stimulated TNF- $\alpha$ in CD8+ cells

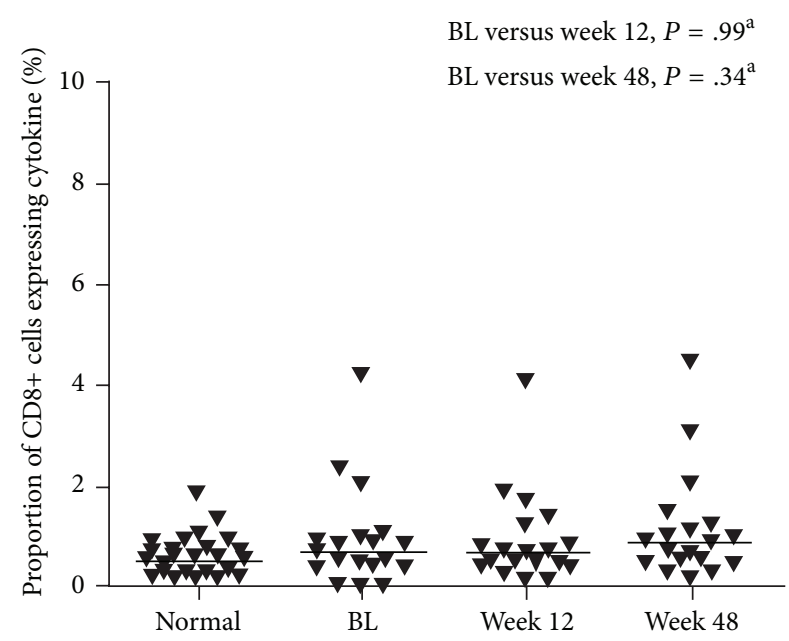

(d) SEB-stimulated IL-2 in CD8+ cells

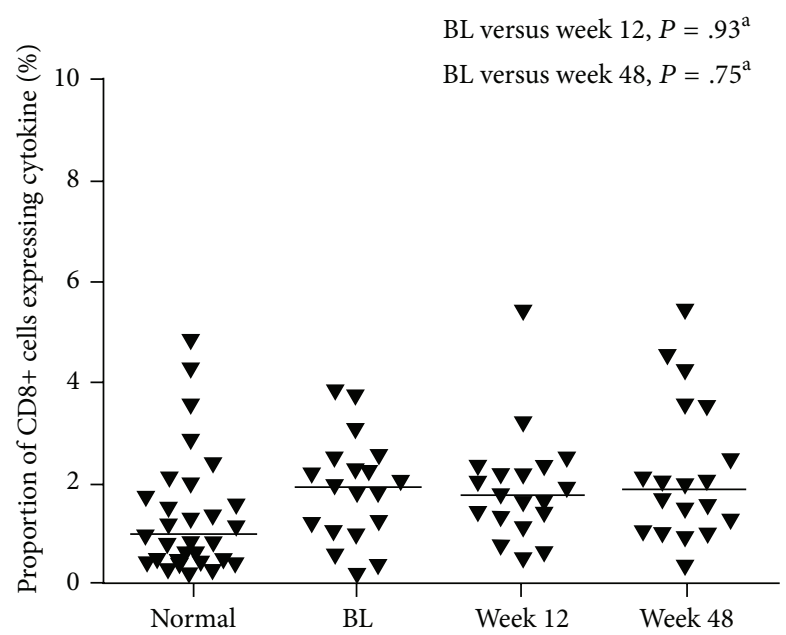

(f) SEB-stimulated IFN- $\gamma$ in CD8+ cells

FIGURE 4: Staphylococcal enterotoxin B-stimulated cytokine expression in virologically suppressed patients. Line represents median; ${ }^{a}$ Wilcoxon rank-sum test; TNF- $\alpha$ : tumor necrosis factor-alpha; IL-2: interleukin-2; IFN- $\gamma$ : interferon-gamma; SEB: staphylococcal enterotoxin B; BL: baseline. 
in the CD4+/CD28- or CD8+/CD28- phenotype was seen, consistent with other studies that have suggested that CD28 expression is not normalized in HIV-1-infected patients who have undergone up to 3 years of ARV therapy [40, 41].

One possible limitation to this study is the small sample size, which may limit data interpretation. The study aimed to enroll 50 women and 50 men, but, due to a delayed start date, after initiation of the GRACE study, the patient pool for this substudy was limited and the enrollment goal was not reached. Nonetheless, the data obtained are similar to those of other trials. Both immune phenotype and function of CD4+ and CD8+ cells were significantly improved in treatmentexperienced patients receiving DRV/r-based therapy, as evidenced by positive changes in the capacity to proliferate and the expression of intracellular cytokines by CD4+ cells. The functional recovery observed in virologically suppressed patients, as assessed by proliferative response and intracellular cytokine expression, was also seen in nonsuppressed patients, although to a lesser degree.

Antiretroviral therapy has been available for 25 years; however, there has been limited research on immune recovery after long-term treatment. Furthermore, the focus of immune recovery has historically been an assessment of CD4+ cell counts. In the current study, in addition to the evaluation of $\mathrm{CD} 4+$ cell counts, CD4+ cell activation (CD38+/HLA-DR+, CD95+), function, and senescence (CD28-) were measured as well as CD8+ cell counts, activation, function, and senescence. It should be noted that, as observed in this trial, despite the improvements in immune phenotype and function seen with ARV therapy, complete normalization of $\mathrm{CD} 4+$ and $\mathrm{CD} 8+$ parameters is rarely achieved in HIV-1-infected individuals [24, 42]. However, we hypothesize that there may be some clinical benefit even in patients who do not experience measurable or significant increases in CD4+ cell counts. It is feasible that, in patients with higher baseline CD4 levels, measurable increases in CD4+ cell counts may not be observed [43].

Previous studies have shown that despite CD4+ cell count normalization, the pretreatment nadir $\mathrm{CD} 4+$ count and level of CD28 CD4+ coexpressing lymphocytes determine ongoing immune competence, including responses to immunization [40]. Despite the successful HIV therapy noted in the GRACE substudy, there seemed to be a higher frequency of the CD8+ CD28- phenotype. This possible treatmentresistant expansion and persistence of cells with a senescence phenotype may have potential for long-term cardiovascular [44], metabolic, and other aging-associated consequences.

This GRACE substudy demonstrates that DRV/r-based therapy improved CD4+ cell recovery and was associated with progressive functional immune recovery over the 48week study period. Thus, initiation of ARV therapy may be required not only to restore immune function, but also to diminish the effects of chronic inflammation.

\section{Disclosure}

This paper was presented at the 5th International AIDS Society Conference on HIV pathogenesis, Treatment and
Prevention. Cape Town, South Africa, July 19-22, 2009, Poster TUPD203.

\section{Conflict of Interests}

Dr. Tsoukas is a consultant for Merck, Abbott, Boehringer Ingelheim, GlaxoSmithKline, Bristol-Myers Squibb, Gilead, Tibotec/Johnson \& Johnson, Novartis, Roche, and Talecris. Ms. Gilbert and Mr. Lewis have no financial conflict of interests. Dr. Hatzakis receives grant/research support from Masimo Biotech. Dr. Falcon is an employee and stockholder of Johnson \& Johnson. Dr. Mrus is an employee and stockholder of Johnson \& Johnson.

\section{Acknowledgments}

The authors would like to thank the patients and their families, the study sites, and the principal investigators for their participation in the trial. The authors would like to acknowledge Gilead for supplying emtricitabine, tenofovir, and emtricitabine/tenofovir. The authors would additionally like to acknowledge internal study support staff, as well as Samantha Taylor, Ph.D., Medicus International New York, for her editorial assistance.

\section{References}

[1] L. Kestens, G. Vanham, C. Vereecken et al., "Selective increase of activation antigens HLA-DR and CD38 on CD4+ CD45RO+ T lymphocytes during HIV-1 infection," Clinical and Experimental Immunology, vol. 95, no. 3, pp. 436-441, 1994.

[2] M. Levacher, F. Hulstaert, S. Tallet, S. Ullery, J. J. Pocidalo, and B. A. Bach, "The significance of activation markers on CD8 lymphocytes in human immunodeficiency syndrome: staging and prognostic value," Clinical and Experimental Immunology, vol. 90, no. 3, pp. 376-382, 1992.

[3] J. V. Giorgi, H.-N. Ho, K. Hirji et al., "CD8+ lymphocyte activation at human immunodeficiency virus type 1 seroconversion: development of HLA-DR+ CD38- CD8+ cells is associated with subsequent stable CD4+ cell levels," Journal of Infectious Diseases, vol. 170, no. 4, pp. 775-781, 1994.

[4] S. A. Klein, J. M. Dobmeyer, T. S. Dobmeyer et al., "Demonstration of the Th1 to Th2 cytokine shift during the course of HIV-1 infection using cytoplasmic cytokine detection on single cell level by flow cytometry," AIDS, vol. 11, no. 9, pp. 1111-1118, 1997.

[5] Z. Liu, W. G. Cumberland, L. E. Hultin, H. E. Prince, R. Detels, and J. V. Giorgi, "Elevated CD38 antigen expression on CD8+ $\mathrm{T}$ cells Is a stronger marker for the risk of chronic HIV disease progression to AIDS and death in the multicenter AIDS Cohort study than CD4+ cell count, soluble immune activation markers, or combinations of HLA-DR and CD38 expression," Journal of Acquired Immune Deficiency Syndromes and Human Retrovirology, vol. 16, no. 2, pp. 83-92, 1997.

[6] M.-L. Dion, J.-F. Poulin, R. Bordi et al., "HIV infection rapidly induces and maintains a substantial suppression of thymocyte proliferation," Immunity, vol. 21, no. 6, pp. 757-768, 2004.

[7] A. Landay, B. Ohlsson-Wilhelm, and J. V. Giorgi, "Application of flow cytometry to the study of HIV infection," AIDS, vol. 4, no. 6, pp. 479-497, 1990. 
[8] J. B. Margolick, A. Munoz, A. D. Donnenberg et al., "Failure of T-cell homeostasis preceding AIDS in HIV-1 infection. The Multicenter AIDS Cohort study," Nature Medicine, vol. 1, no. 7, pp. 674-680, 1995.

[9] L. Kestens, G. Vanham, P. Gigase et al., "Expression of activation antigens, HLA-DR and CD38, on CD8 lymphocytes during HIV-1 infection," AIDS, vol. 6, no. 8, pp. 793-797, 1992.

[10] V. Appay, J. R. Almeida, D. Sauce, B. Autran, and L. Papagno, "Accelerated immune senescence and HIV-1 infection," Experimental Gerontology, vol. 42, no. 5, pp. 432-437, 2007.

[11] S. P. Aries, B. Schaaf, C. Muller, R. H. Dennin, and K. Dalhoff, "Fas (CD95) expression on CD4+ T cells from HIVinfected patients increases with disease progression," Journal of Molecular Medicine, vol. 73, no. 12, pp. 591-593, 1995.

[12] T. H. Mogensen, J. Melchjorsen, C. S. Larsen, and S. R. Paludan, "Innate immune recognition and activation during HIV infection,” Retrovirology, vol. 7, article 54, 2010.

[13] M. E. Peter, A. Ehret, C. Berndt, and P. H. Krammer, "AIDS and the death receptors," British Medical Bulletin, vol. 53, no. 3, pp. 604-616, 1997.

[14] Z. Bentwich, A. Kalinkovich, Z. Weisman, and Z. Grossman, "Immune activation in the context of HIV infection," Clinical and Experimental Immunology, vol. 111, no. 1, pp. 1-2, 1998.

[15] Z. Grossman, M. Meier-Schellersheim, W. E. Paul, and L. J. Picker, "Pathogenesis of HIV infection: what the virus spares is as important as what it destroys," Nature Medicine, vol. 12, no. 3, pp. 289-295, 2006.

[16] M. D. Hazenberg, D. Hamann, H. Schuitemaker, and F. Miedema, "T cell depletion in HIV-1 infection: how CD4+ T cells go out of stock," Nature Immunology, vol. 1, no. 4, pp. 285$289,2000$.

[17] L. A. Trimble, P. Shankar, M. Patterson, J. P. Daily, and J. Lieberman, "Human immunodeficiency virus-specific circulating $\mathrm{CD} 8 \mathrm{~T}$ lymphocytes have down-modulated $\mathrm{CD} 3 \zeta$ and CD28, key signaling molecules for T-cell activation," Journal of Virology, vol. 74, no. 16, pp. 7320-7330, 2000.

[18] J. H. Vingerhoets, G. L. Vanham, L. L. Kestens et al., "Increased cytolytic T lymphocyte activity and decreased B7 responsiveness are associated with CD28 down-regulation on CD8+ T cells from HIV-infected subjects," Clinical and Experimental Immunology, vol. 100, no. 3, pp. 425-433, 1995.

[19] S. T. Parish, J. E. Wu, and R. B. Effros, "Sustained CD28 expression delays multiple features of replicative senescence in human CD8 T lymphocytes," Journal of Clinical Immunology, vol. 30, no. 6, pp. 798-805, 2010.

[20] V. I. Avelino-Silva, Y.-L. Ho, T. J. Avelino-Silva, and S. D. S. Santos, "Aging and HIV infection," Ageing Research Reviews, vol. 10, no. 1, pp. 163-172, 2011.

[21] K. L. Wood, H. L. Twigg III, and A. I. Doseff, "Dysregulation of CD8+ lymphocyte apoptosis, chronic disease, and immune regulation," Frontiers in Bioscience, vol. 14, no. 10, pp. 3771-3781, 2009.

[22] J. V. Giorgi, Z. Liu, L. E. Hultin, W. G. Cumberland, K. Hennessey, and R. Detels, "Elevated levels of CD38+CD8+ T cells in HIV infection add to the prognostic value of low CD4+ T cell levels: results of 6 years of follow-up," Journal of Acquired Immune Deficiency Syndromes, vol. 6, no. 8, pp. 904-912, 1993.

[23] M. Clerici and G. M. Shearer, " $\mathrm{A} \mathrm{T}_{\mathrm{H}} 1 \rightarrow \mathrm{T}_{\mathrm{H}} 2$ switch is a critical step in the etiology of HIV infection," Immunology Today, vol. 14, no. 3, pp. 107-111, 1993.
[24] B. Autran, G. Carcelain, T. S. Li et al., "Positive effects of combined antiretroviral therapy on CD4+ T cell homeostasis and function in advanced HIV disease," Science, vol. 277, no. 5322, pp. 112-116, 1997.

[25] J. Estaquier, J.-D. Leliévre, F. Petit et al., "Effects of antiretroviral drugs on human immunodeficiency virus type 1-induced CD4+ T-cell death," Journal of Virology, vol. 76, no. 12, pp. 5966-5973, 2002.

[26] A. D. Badley, K. Parato, D. W. Cameron et al., "Dynamic correlation of apoptosis and immune activation during treatment of HIV infection," Cell Death and Differentiation, vol. 6, no. 5, pp. 420-432, 1999.

[27] M. Goicoechea, D. M. Smith, L. Liu et al., "Determinants of $\mathrm{CD} 4+\mathrm{T}$ cell recovery during suppressive antiretroviral therapy: association of immune activation, T cell maturation markers, and cellular HIV-1 DNA," Journal of Infectious Diseases, vol. 194, no. 1, pp. 29-37, 2006.

[28] S. A. Riddler, R. Haubrich, A. G. DiRienzo et al., "Class-sparing regimens for initial treatment of HIV-1 infection," The New England Journal of Medicine, vol. 358, no. 20, pp. 2095-2106, 2008.

[29] M. Pichenot, S. Deuffic-Burban, L. Cuzin, and Y. Yazdanpanah, "Efficacy of new antiretroviral drugs in treatment-experienced HIV-infected patients: a systematic review and meta-analysis of recent randomized controlled trials," HIV Medicine, vol. 13, no. 3, pp. 148-155, 2012.

[30] J. M. Llibre, M. J. Buzón, M. Massanella et al., “Treatment intensification with raltegravir in subjects with sustained HIV-1 viraemia suppression: a randomized 48-week study," Antiviral Therapy, vol. 17, no. 2, pp. 355-364, 2012.

[31] H. Hatano, T. L. Hayes, V. Dahl et al., "A randomized, controlled trial of raltegravir intensification in antiretroviral-treated, HIVinfected patients with a suboptimal CD4+ T cell response," Journal of Infectious Diseases, vol. 203, no. 7, pp. 960-968, 2011.

[32] H. Byakwaga, M. Kelly, D. F. J. Purcell et al., "Intensification of antiretroviral therapy with raltegravir or addition of hyperimmune bovine colostrum in HIV-infected patients with suboptimal CD4+ T-cell response: a randomized controlled trial," Journal of Infectious Diseases, vol. 204, no. 10, pp. 15321540, 2011.

[33] J. Currier, D. A. Bridge, D. Hagins et al., "Sex-based outcomes of Darunavir-Ritonavir therapy: a single-group trial," Annals of Internal Medicine, vol. 153, no. 6, pp. 349-357, 2010.

[34] J. B. Angel, K. G. Parato, A. Kumar et al., "Progressive human immunodeficiency virus-specific immune recovery with prolonged viral suppression," Journal of Infectious Diseases, vol. 183, no. 4, pp. 546-554, 2001.

[35] H. Ullum, T. Katzenstein, H. Aladdin et al., "Immunological changes in Human Immunodeficiency Virus (HIV)-infected individuals during HIV-specific protease inhibitor treatment," Scandinavian Journal of Immunology, vol. 49, no. 5, pp. 539-547, 1999.

[36] R. C. Kaplan, C. M. Parrinello, H. N. Hodis et al., "Impact of HAART initiation on immune regulation (activation/senescence) in aging HIV-infected women: Women's Interagency HIV study," in Proceedings of the 19th Conference on Retroviruses and Opportunistic Infections, Seattle, Wash, USA, 2012.

[37] C. Garrido, N. Rallón, V. Soriano et al., "Mechanisms involved in CD4 gains in HIV-infected patients switched to raltegravir," AIDS, vol. 26, no. 5, pp. 551-557, 2012. 
[38] R. T. Steigbigel, D. A. Cooper, P. N. Kumar et al., "Raltegravir with optimized background therapy for resistant HIV-1 infection," The New England Journal of Medicine, vol. 359, no. 4, pp. 339-354, 2008.

[39] M.-L. Gougeon, H. Lecoeur, and Y. Sasaki, "Apoptosis and the CD95 system in HIV disease: impact of Highly Active AntiRetroviral Therapy (HAART)," Immunology Letters, vol. 66, no. 1-3, pp. 97-103, 1999.

[40] C. G. Lange, M. M. Lederman, K. Medvik et al., "Nadir CD4+ T-cell count and numbers of CD28+ CD4+ T-cells predict functional responses to immunizations in chronic HIV1 infection," AIDS, vol. 17, no. 14, pp. 2015-2023, 2003.

[41] T. Niehues, G. Horneff, S. Knipp, O. Adams, and V. Wahn, "Treatment-resistant expansion of CD8+CD28-cells in pediatric HIV infection," Pediatric Research, vol. 47, no. 3, pp. 418421, 2000.

[42] C. G. Lange and M. M. Lederman, "Immune reconstitution with antiretroviral therapies in chronic HIV-1 infection," Journal of Antimicrobial Chemotherapy, vol. 51, no. 1, pp. 1-4, 2003.

[43] A. Hill, J. Montaner, M. Lederman, A. Cutrell, S. Tortell, and D. Thorborn, "Discordant CD4/RNA responses to HAART are strongly associated with high baseline CD4 count and low HIV RNA: analysis of 406 naive patients," in Proceedings of the 3 rd International Workshop on HIV Drug Resistance and Treatment Strategies, San Diego, Calif, USA, 1999.

[44] R. C. Kaplan, E. Sinclair, A. L. Landay et al., "T cell activation and senescence predict subclinical carotid artery disease in HIV-infected women," Journal of Infectious Diseases, vol. 203, no. 4, pp. 452-463, 2011. 


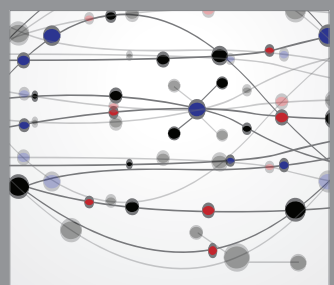

The Scientific World Journal
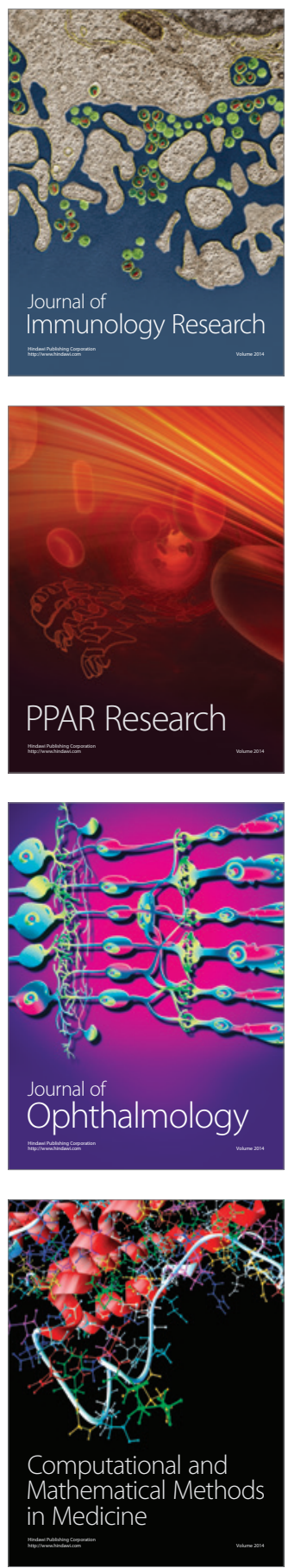

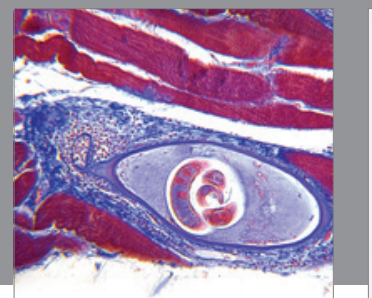

Gastroenterology

Research and Practice
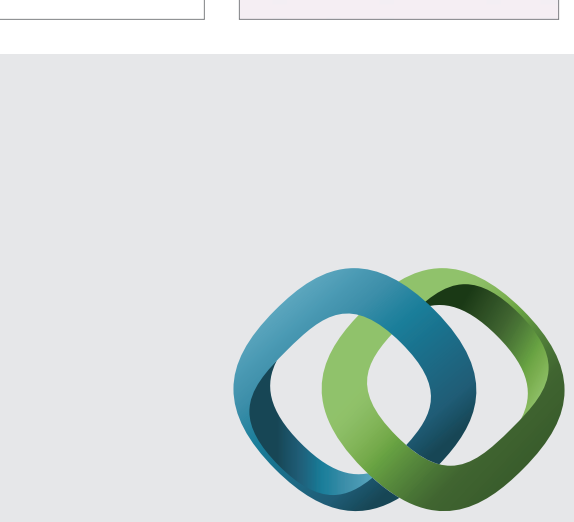

\section{Hindawi}

Submit your manuscripts at

http://www.hindawi.com
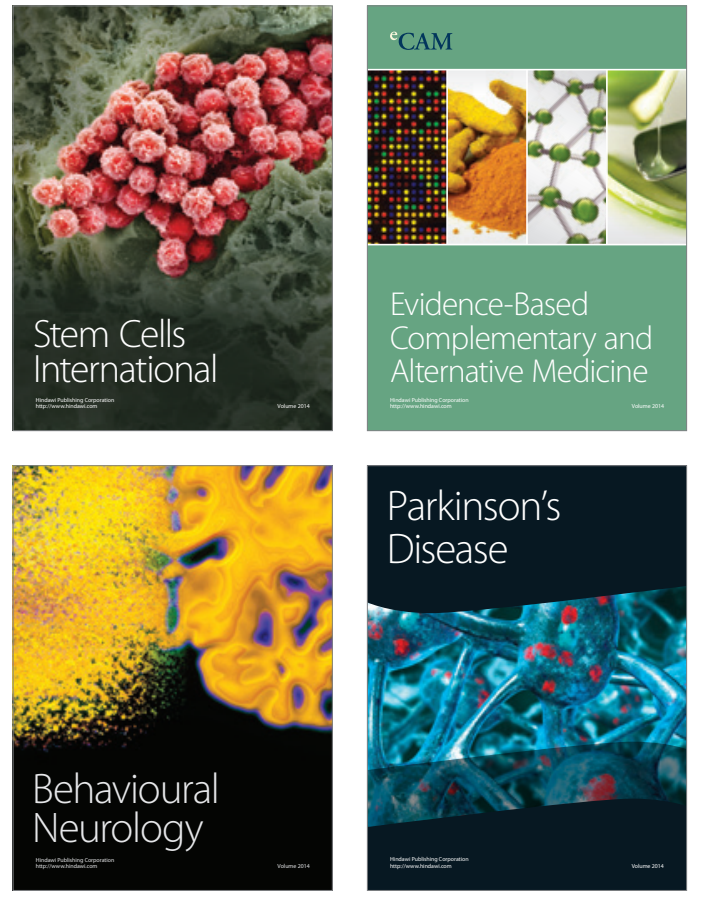
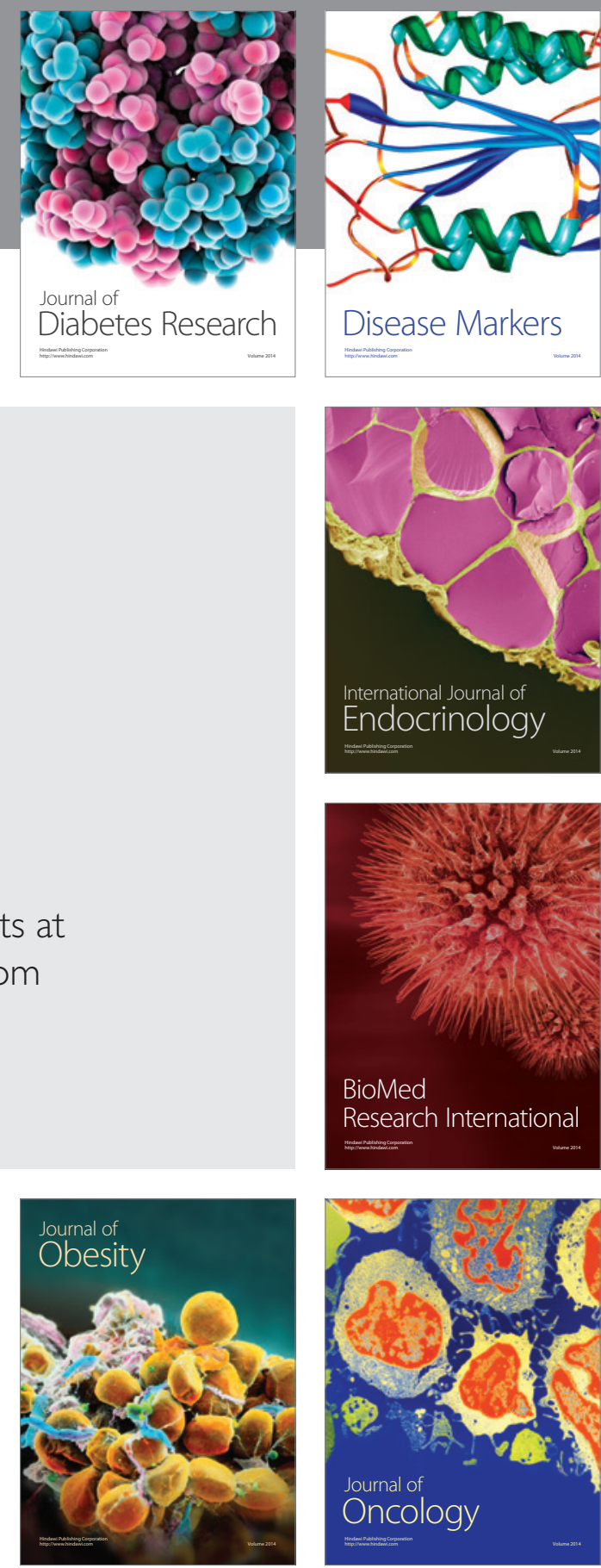

Disease Markers
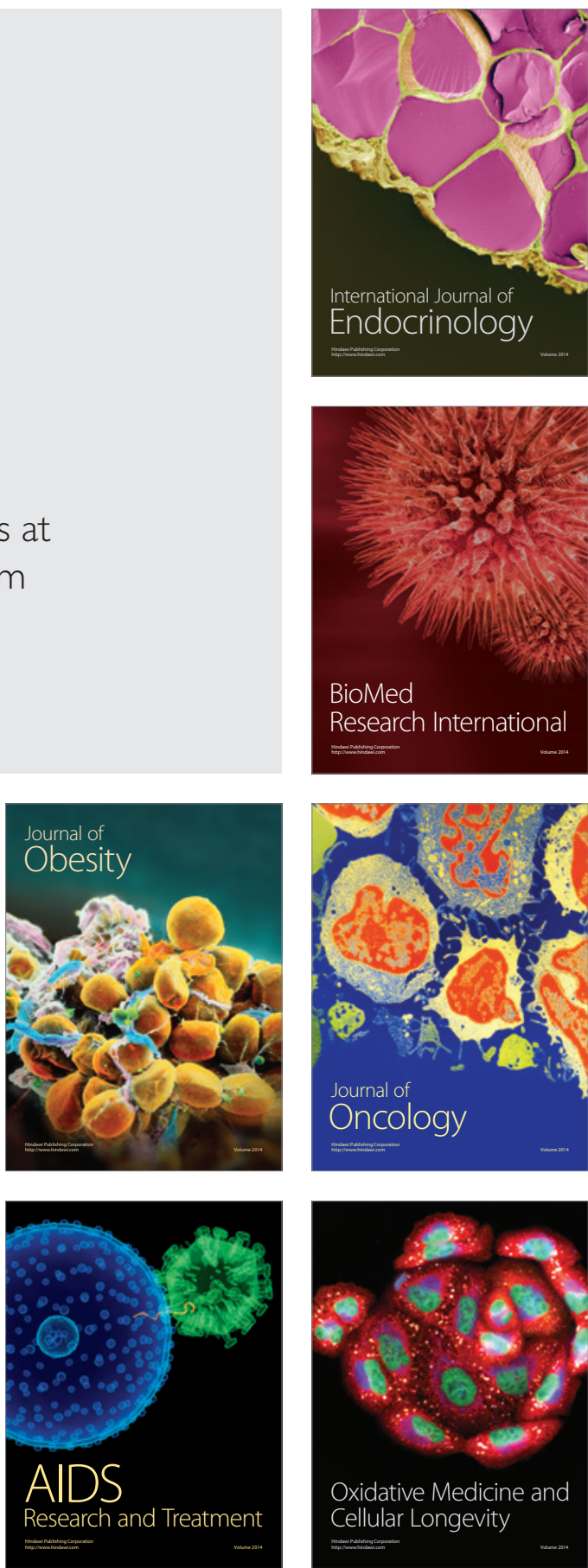